\title{
BIOSSEGURANÇA EM SALÕES DE BELEZA: AVALIAÇÃO DA ESTRUTURA E DISPOSITIVOS
}

\section{BIOSAFETY IN BEAUTY SALONS: STRUCTURE AND DEVICES EVALUATION}

\section{BIOSEGURIDAD LOS SALONES: ESTRUCTURA DE LA EVALUACIÓN Y DISPOSITIVOS}

\author{
Juliana Ladeira Garbaccio ${ }^{1}$, Adriana Cristina de Oliveira ${ }^{2}$
}

\section{RESUMO}

Objetivo: avaliar a estrutura física, os dispositivos presentes em salões beleza e a dinâmica da limpeza/desinfecção de superfícies e mobiliários nesses estabelecimentos. Método: Trata-se de um estudo transversal, envolvendo 235 salões de beleza. Foram entrevistadas manicures/pedicures e observados a estrutura física dos salões e métodos de esterilização. Resultados: 0 tamanho médio dos salões foi de $67 \mathrm{~m}^{2}$, sendo que $49 \%$ dispunham de sala exclusiva para manicures/pedicures; $2 \%$ não possuíam banheiro; $30 \%$ dispunham de uma única pia e, em $43 \%$ deles, havia um local próprio destinado à limpeza de artigos. 0 método de esterilização utilizado, predominantemente, foi o calor seco $(61,7 \%)$, sendo que, em $35,3 \%$ dos casos havia autoclave e, em $33,2 \%$, foi realizada a validação da esterilização pelo uso do indicador biológico. A limpeza de superfícies entre clientes foi referida por $2 \%$ dos estabelecimentos. Conclusão: A estrutura dos salões precisa ser revista, os espaços parecem não atender a demandas mínimas para as atividades desenvolvidas, com condições adequadas de funcionamento, o que aumenta o risco biológico, como a ausência de sanitários ou o compartilhamento de uma única pia para atividades distintas. Ações educativas e orientações seguras de funcionamento visando à segurança da saúde de profissionais e clientes são necessárias e emergenciais.

Descritores: Centros de embelezamento e estética; Podiatria; Exposição a agentes biológicos; Precauções universais.

\begin{abstract}
Objectives: to evaluate the physical structure, devices present in beauty salons and the dynamics of surfaces and furniture cleaning/disinfection in these establishments. Method: This was a cross-sectional study, involving 235 beauty salons. We interviewed manicurists/pedicurists, observing the physical structure of the salons and sterilization methods. Results: The average size of the salons was $67 \mathrm{~m}^{2}, 49 \%$ had an exclusive room for manicurists/pedicurists; $2 \%$ did not have a bathroom; $30 \%$ had a single sink for all types of use, and in $43 \%$ of them, there was a separate space for cleaning items. Dry heat was the predominant method of sterilization (61.7\%), in $35.3 \%$ of the cases, there was an autoclave, and in $33.2 \%$, the sterilization was validated using the biological indicator. Cleaning of surfaces between customers was reported by $2 \%$ of the establishments. Conclusion: The structure of the salons needs to be reviewed, the spaces do not seem to meet the minimum demands for the developed activities, with adequate operating conditions, which increases the biological risk, such as the absence of toilets or sharing a single sink for different activities. Educational actions and safe guidance for operation aiming at the health safety of professionals and clients are necessary and emergency.
\end{abstract}

Descriptors: Beauty and aesthetics centers; Podiatry; Exposure to biological agents; Universal precautions.

\section{RESUMEN}

Objetivo: Evaluar la estructura física, los equipamientos utilizados en los salones de belleza y la dinámica de la limpieza/desinfección de superficies y mobiliario en estos establecimientos. Método: Se realizó un estudio transversal con 235 salones. Manicuristas y pedicuristas fueron entrevistados, observando la estructura física de las salas y métodos de esterilización. Resultados: Las áreas de trabajo promedio fueron de $67 \mathrm{~m}^{2}$, de los cuales el $49 \%$ tenían áreas exclusivas para manicuristas/pedicuristas; $2 \%$ no tenían baño; $30 \%$ tenían solamente un fregadero, y en el $43 \%$ de ellos, había un sitio propio para la limpieza de los elementos. El método más utilizado de esterilización es por calor seco $(61,7 \%)$, y había el método autoclave (35,3\%), y en el $33,2 \%$, la validación de la esterilización fue utilizada por medio del indicador biológico. La limpieza de superficies entre los clientes fue informada en el $2 \%$ de los establecimientos. Conclusión: La estructura de los salones necesita ser revisada, los espacios parecen no cumplir los requisitos mínimos para desarrollar las actividades en óptimas condiciones, aumentando el riesgo biológico, como la falta de baños o la utilización del único fregadero para diferentes actividades. Acciones educativas y orientaciones seguras de funcionamiento visando a la salud de los profesionales y clientes son necesarias y de urgencia.

Descriptores: Centros de embellecimiento y estética; Podiatría; Exposición a agentes biológicos; Precauciones universales

${ }^{1}$ Graduada em Enfermagem e Odontologia. Doutora em Enfermagem pela Universidade Federal de Minas Gerais. Docente na Pontifícia Universidade Católica de Minas Gerais - PUC/MG. ${ }^{2}$ Graduada em Enfermagem. Doutorado em Enfermagem pela Universidade de São Paulo. Docente na Universidade Federal de Minas Gera is. 


\section{INTRODUÇÃO}

Os estabelecimentos que prestam serviços na área de beleza e estética fazem parte do cenário do mundo atual e, cada vez mais, um contingente maior de pessoas os frequenta. No Brasil, sabe-se que a população valoriza a estética corporal: alguns precisam estar em perfeita sintonia com os padrões estabelecidos para alcançar um patamar socioeconômico e outros, para melhorar a autoestima ${ }^{(1)}$. Estudos realizados nos Estados Unidos e Canadá evidenciam que a aparência tem impactos positivos como, por exemplo, nos rendimentos dos trabalhadores e na empregabilidade ${ }^{(1)}$.

Recentemente, as funções de cabeleireiro, barbeiro, esteticista, manicure, pedicure, depilador e maquiador foram reconhecidas em todo o território nacional brasileiro por meio da Lei n. ${ }^{\circ} 12.592$ de 2012, e grande parte desses profissionais exercem suas atividades em salões de beleza ${ }^{(2)}$.

Os profissionais da estética corporal manipulam áreas do corpo humano habitadas por microrganismos, tanto da microbiota normal quanto da transitória, que podem ser agentes potencialmente infecciosos e transmitidos por contato direto, por artigos e substâncias contaminadas ou por acidentes com materiais perfurocortantes ${ }^{(3,4)}$. Portanto, a adesão às medidas de biossegurança é essencial no sentido de preservar a saúde de trabalhadores e clientes e, para isso, alguns pontos como a estrutura física do salão, a presença de dispositivos e equipamentos em boas condições de uso, que permitem procedimentos de limpeza/desinfecção, fazem-se necessários. De acordo com a Lei . $^{\circ} 3.632$, de 30 de julho de 1999, o salão precisa atender às exigências mínimas de segurança sanitária, que incluem: a adequada relação entre a dimensão do estabelecimento versus o número de funcionários e clientes; iluminação adequada para a execução dos serviços; banheiro; áreas para 0 processamento (limpeza, desinfecção e esterilização) de artigos; número de pias e localização adequada que permitam a higienização das mãos ${ }^{(3,4)}$.

No âmbito da saúde pública, especificamente no que tange a aspectos de vigilância sanitária, entende-se que a limpeza e a desinfecção correta de superfícies e objetos em salões de beleza, com técnicas preconizadas pelas agências de saúde, são essenciais e obrigatórias na prevenção da disseminação de patógenos. Com isso, algumas precauções devem ser tomadas visando à redução do risco de contaminações, como a higienização das mãos, o uso de equipamentos de proteção individual, vacinação dos profissionais, esterilização de artigos, limpeza/desinfecção do ambiente e estrutura física adequada dos estabelecimentos $^{(5)}$.

Para o segmento da beleza e estética, diferente da vasta literatura encontrada no âmbito hospitalar, há uma ausência de pesquisas bem delineadas direcionadas à avaliação da estrutura física dos salões de beleza e, também, uma escassez de estudos sobre o conhecimento e adesão dos profissionais às medidas de biossegurança. Ainda assim, os poucos trabalhos que abordam esse tema demonstram uma realidade semelhante à da área da saúde quanto à baixa adesão a algumas medidas de biossegurança ${ }^{(3,5)}$. Entretanto, diferem no aspecto da formação técnica, revelando profissionais do segmento da beleza com parcos conhecimentos e, portanto, desinformados sobre protocolos de biossegurança elaborados por organizações nacionais e internacionais responsáveis pela recomendação de prevenção de agravos à saúde da população ${ }^{(6,7)}$.

Assim, coloca-se como pergunta norteadora desta pesquisa: Como se encontram a estrutura física, a limpeza, a desinfecção do ambiente, de materiais e os dispositivos relacionados à biossegurança em salões de beleza?

Os problemas relacionados à estrutura do funcionamento de salões de beleza que impactam na segurança da classe trabalhadora e dos clientes passam pela precária formação profissional, além do desconhecimento acerca das exigências sanitárias e dos riscos de infecções advindas da susceptibilidade a desequilíbrios constantes da tríade epidemiológica: agente, hospedeiro e meio ambiente ${ }^{(3)}$.

Esta pesquisa teve, portanto, como objetivo, avaliar a estrutura física, os dispositivos presentes em salões beleza e a dinâmica da limpeza/desinfecção de superfícies e mobiliários nesses estabelecimentos. A partir da avaliação realizada, entende-se que reflexões possam ser construídas, estimulando outros estudos sobre essa temática, e que os resultados possam subsidiar novas discussões e o avanço do 
conhecimento para o segmento da beleza, para os órgãos e profissionais de vigilância à saúde.

\section{MÉTODO}

Trata-se de uma pesquisa transversal, conduzida no período entre junho de 2012 a março de 2013, em salões de beleza em Belo Horizonte, no estado de Minas Gerais, Brasil, após aprovação junto ao Comitê de Ética em Pesquisa da Universidade Federal de Minas Gerais (CAAE - parecer no 0195.0.203.000/2011).

Um único profissional (manicure/pedicure) foi entrevistado por salão de beleza numa amostra de 235 estabelecimentos, calculada com intervalo de confiança de $95 \%$, desvio padrão de 0,5 e erro máximo de estimativa de 0,05 a partir de uma população de 600 salões, com cadastro e autorização de funcionamento fornecido pela Secretaria Municipal Adjunta de Regulação Urbana da Prefeitura de Belo Horizonte (PBH), em 2010.

Cada salão foi escolhido a partir de uma seleção aleatória simples, entre os 600 cadastrados. Tomou-se o cuidado de mapear os centros de beleza e estética por bairros, de forma a obter uma amostra geograficamente distribuída em todas as regiões da cidade, a qual, no censo de 2010, registrou 2.475 milhões de habitantes ${ }^{(8)}$. Para confirmação concomitante da existência e endereço dos estabelecimentos, foram realizadas ligações telefônicas para todos os salões.
Cinco entrevistadores foram devidamente treinados e a todos foi distribuído o plano de visitas com os endereços dos estabelecimentos sorteados. Em caso de recusa ou quando algum salão se encontrava fechado ou não era localizado, utilizou-se o critério de substituição pelo próximo estabelecimento localizado à esquerda, desde que possuísse cadastro de funcionamento junto à $\mathrm{PBH}$.

Como critério para coleta de dados, estabeleceu-se a entrevista de manicures/pedicures, por serem os profissionais mais presentes nos salões de beleza com, no mínimo, um ano de experiência nessas profissões, com idade acima de 18 anos, do sexo masculino ou feminino, proprietário ou funcionário do salão. As entrevistas ocorreram após o convite verbal aos proprietários dos estabelecimentos e aos profissionais informantes, explicando os objetivos e a relevância da pesquisa. Após o aceite, foi apresentado aos profissionais o termo de consentimento livre e esclarecido.

Para a entrevista (presencial), adotou-se um questionário estruturado contendo questões abertas e de múltipla escolha relativas às características gerais do estabelecimento e do entrevistado e questões sobre a estrutura e dispositivos presentes nos estabelecimentos, com respostas validadas por observação, apresentados na Figura 1.

Figura 1 - Descrição dos tópicos de avaliação da estrutura do salão por manicures/pedicures, com respostas validadas ou não por observação direta. Belo Horizonte - MG, 2013.

\begin{tabular}{|c|c|}
\hline Questões & Respostas \\
\hline \multicolumn{2}{|c|}{ Características Gerais } \\
\hline N. ${ }^{\circ}$ de profissionais no estabelecimento em dias de maior demanda & \\
\hline Tempo de trabalho do profissional entrevistado no salão participante & \\
\hline Serviços oferecidos no salão & $\begin{array}{l}\text { Manicure/pedicure, } \\
\text { cabeleireiro, depilação, estótica, } \\
\text { barbearia, outros. }\end{array}$ \\
\hline \multicolumn{2}{|l|}{ Sexo da manicure entrevistado } \\
\hline \multicolumn{2}{|l|}{ Idade da manicure entrevistado } \\
\hline Participação da manicure no estabelecimento & $\begin{array}{l}\text { Proprietário, sócio, empregado formal, } \\
\text { empregado informal }\end{array}$ \\
\hline \multicolumn{2}{|c|}{ Estrutura do salão - com respostas validadas por observação } \\
\hline Qual é o tamanho aproximado do estabelecimento em $\mathrm{m}^{2}$ ? & \\
\hline Há recepção no estabelecimento? & (0)Não (1) Sim \\
\hline
\end{tabular}




\begin{tabular}{|c|c|}
\hline $\begin{array}{l}\text { Salas de atendimento individualizada para manicures, cabelereiros, } \\
\text { esteticista? }\end{array}$ & (0)Não (1) Sim \\
\hline $\begin{array}{l}\text { O espaço é suficiente para mais de uma manicure trabalhar } \\
\text { simultaneamente? }\end{array}$ & (0)Não (1) Sim \\
\hline Quantos banheiros há no estabelecimento? & \\
\hline Os banheiros são azulejados/revestidos com acabamento de fácil limpeza? & (0)Não (1) Sim \\
\hline $\begin{array}{l}\text { Revestimento paredes/tetos revestidos: resistente, liso, cores claras, lavável } \\
\text { impermeáveis, conservados. }\end{array}$ & (0)Não (1) Sim \\
\hline Os móveis são de material impermeável e de fácil limpeza? & (0)Não (1) Sim \\
\hline Há local exclusivo para guardar material de limpeza? & (0)Não (1) Sim \\
\hline $\begin{array}{l}\text { Há uma sala com pia própria e bancada impermeável para lavagem de } \\
\text { materiais/instrumentais contaminados? }\end{array}$ & (0)Não (1) Sim \\
\hline $\begin{array}{l}\text { A lavagem de todo o material, instrumental e panos de chão é feita na única } \\
\text { pia do estabelecimento? }\end{array}$ & (0)Não (1) Sim \\
\hline Onde esta pia fica localizada? & \\
\hline $\begin{array}{l}\text { Há local separado (sala) para abrigar um equipamento de esterilização (ex.: } \\
\text { autoclave, forno, estufa)? }\end{array}$ & $\begin{array}{l}\text { (0) Não Onde fica: } \\
\text { (1) Sim }\end{array}$ \\
\hline Qual equipamento é usado com objetivo de esterilização? & \\
\hline Há caixa própria para descarte de material perfurante ou cortante? & (0)Não (1) Sim \\
\hline As lixeiras possuem tampas acionadas por pedal e localizadas em fácil acesso? & (0)Não (1) Sim \\
\hline \multicolumn{2}{|l|}{ Limpeza do salão - questões de relato sem validação por observação } \\
\hline $\begin{array}{l}\text { Para limpeza de superfícies como mesas, prateleiras e bancadas, você utiliza } \\
\text { em geral: }\end{array}$ & $\begin{array}{l}\text { (1) água e sabão; (2) água, sabão e um } \\
\text { desinfetante; (3) álcool absoluto; (4) } \\
\text { álcool 70\%; } \\
\text { (5) espanador ou algum tecido; } \\
\text { (6) não há um único produto } \\
\text { específico, depende do que foi } \\
\text { comprado como produto de limpeza; } \\
\text { (888) Não sabe; (999) Não respondeu }\end{array}$ \\
\hline \multicolumn{2}{|c|}{ Qual frequência da limpeza das superfícies relacionadas na questão anterior? } \\
\hline $\begin{array}{l}\text { Como é realizada a limpeza do piso? } \\
\text { II.51a) É varrido com vassoura? } \\
\text { II.51b) É usado produto químico? }\end{array}$ & $\begin{array}{l}\text { (0) Não (1) Sim } \\
\text { (0) Não (1) Sim } \\
\text { (1.1) água e sabão; (1.2) água, sabão e } \\
\text { um desinfetante; (888) Não sabe; (999) } \\
\text { Não respondeu }\end{array}$ \\
\hline $\begin{array}{l}\text { Qual a frequência de limpeza das superfícies relacionadas na questão } \\
\text { anterior? }\end{array}$ & \\
\hline Outras observações que julgar impor & \\
\hline
\end{tabular}

Fonte: Dados da pesquisa.

As respostas das questões abertas e fechadas foram quantificadas e analisadas descritivamente no programa statistical package for the social sciences (Spss/pc) versão 13.0. Variáveis contínuas foram tratadas por estatística descritiva e medidas de tendência central.

Este estudo disponibilizou ao proprietário do salão de beleza que possuía a autoclave, a oportunidade de validar um processo de esterilização do equipamento, por meio de teste biológico. Um pacote teste foi produzido utilizando-se uma compressa, o indicador do teste de leitura de três horas, e uma embalagem de papel crepado. O pacote foi colocado no equipamento junto com os artigos a serem esterilizados, sendo solicitados o acionamento do aparelho e a execução de procedimento da técnica de esterilização, como são realizados rotineiramente no estabelecimento. A incubação e a leitura do indicador foram realizadas de acordo com as instruções do fabricante do teste biológico empregado.

\section{RESULTADOS E DISCUSSÂO}

Foram visitados 322 salões de beleza com alvará de funcionamento em Belo Horizonte, e 235 participaram da pesquisa, segundo cálculo amostral. Dos salões visitados, 177 constavam na planilha fornecida pela prefeitura (102 participaram, 31 recusaram e 44 não foram localizados). Para substituir as recusas e os salões 
não localizados, foram visitados outros 145 salões, também com alvará não constante na planilha da PBH, mas inseridos na planilha de controle, e seguindo o critério de substituição definido no método da pesquisa. Destes, 133 responderam ao questionário e 12 não se dispuseram a participar.
Responderam ao questionário 235 manicures/pedicures, todas do sexo feminino, com idade entre 18 e 69 anos (mediana - 31 anos; média - 32,6 anos), 58,7\% trabalhavam no salão visitado há dois anos ou menos, $75,7 \%$ possuíam emprego informal representado pela prestação de serviço sem vínculo empregatício. Demais dados são apresentados na Tabela 1.

Tabela 1- Perfil sociodemográfico, laboral e de formação das manicures/pedicures participantes do estudo. Belo Horizonte - MG, 2013. Total $=235$.

\begin{tabular}{|c|c|c|c|c|c|}
\hline Variáveis Sociodemográficas & $n$ & $\%$ & Variáveis laboral e de formação & $n$ & $\%$ \\
\hline Sexo & & & Tempo de trabalho no ramo (mediana) & & \\
\hline \multirow[t]{2}{*}{ Feminino } & 235 & 100 & $\leq 10$ anos & 139 & 59,1 \\
\hline & & & $>10$ anos & 96 & 40,9 \\
\hline Faixa etária (mediana) & & & Tempo de trabalho no salão (mediana) & & \\
\hline$\leq 31$ anos & 119 & 50,6 & $\leq 2$ anos & 138 & 58,7 \\
\hline$>31$ anos & 116 & 49,4 & $>2$ anos & 97 & 41,3 \\
\hline Estado civil & & & Trabalha em outro salão & & \\
\hline Solteira & 108 & 46,0 & Sim & 4 & 1,7 \\
\hline Casada/amasiada & 107 & 45,5 & Não & 231 & 98,3 \\
\hline Viúva/divorciada & 20 & 20,0 & & & \\
\hline Número de filhos & & & Carga de trabalho/ dia & & \\
\hline Nenhum & 84 & 35,7 & $\leq 6$ horas & 21 & 8,9 \\
\hline Um & 60 & 25,5 & 8 horas & 122 & 51,9 \\
\hline Dois & 55 & 23,4 & $>8$ horas & 92 & 39,1 \\
\hline$\geq$ Três & 36 & 15,3 & & & \\
\hline Escolaridade & & & Participação no estabelecimento & & \\
\hline 10 Grau Incompleto & 22 & 9,4 & Emprego informal & 178 & 75,7 \\
\hline 10 Grau Completo & 44 & 18,7 & Emprego formal & 27 & 11,5 \\
\hline 2o Grau Incompleto & 36 & 15,3 & Sócio & 18 & 7,7 \\
\hline 2ㅇ Grau Completo & 125 & 53,2 & Proprietário & 12 & 5,1 \\
\hline Superior & 8 & 3,4 & & & \\
\hline \multicolumn{6}{|l|}{ Formação profissional } \\
\hline Curso regular profissionalizante & 80 & 34,0 & & & \\
\hline Não regular/ informal & 155 & 66,0 & & & \\
\hline
\end{tabular}

Fonte: Dados da pesquisa.

Os dados sociodemográficos, laborais e de formação corroboram aos de outros estudos, confirmando o caráter feminino, a pouca qualificação na formação profissional, longa atuação na profissão ${ }^{(5,7)}$. A informalidade do trabalho reforça uma característica da profissão que, apesar de antiga, não tem assegurado o exercício disciplinado por legislação própria, com direitos, deveres e garantias. Ela foi reconhecida, mas não ainda foi regulamentada para atender às especificidades do trabalho(2).

Os estabelecimentos participantes ofereciam, além do serviço de manicures/pedicures, serviços de cabeleireiros (98,3\%), depilação (82,6\%), estética $(50,6 \%)$, barbearia $(21 \%)$ e podologia $(10,6 \%)$. Os salões comportavam uma média de 6,5 funcionários e, nos dias de maior demanda de clientes (quinta- 
feira a sábado), o número de profissionais aumentava para 7,2. A maioria, então, dos estabelecimentos ofertava mais de um tipo de serviço, além do cuidado com as unhas (manicure/pedicure), havendo, portanto, uma maior circulação de pessoas nestes locais. Isto implica cuidados adicionais como: maior espaço físico, que deve comportar profissionais e clientes, e atender às exigências ergonômicas e higiênicas ${ }^{(9,10)}$.

Observou-se que os salões de beleza possuíam as mais diversas estruturas físicas, organizações e ofertas de serviços de embelezamento, sendo que, possivelmente, os ambientes foram adaptados a partir de estruturas domiciliares ou de imóveis que não foram projetados e construídos para abrigar um serviço que demanda um mínimo de cuidado frente ao risco da transmissão de patógenos. O tamanho médio dos salões era de $67 \mathrm{~m}^{2}$ (12 a $200 \mathrm{~m}^{2}$ ), sendo que, para $68 \%$ deles, havia recepção, $49 \%$ disponibilizavam uma sala de atendimento individualizada para os clientes de manicures/pedicures e, em $89 \%$ dos salões, o espaço físico permitia a prestação de serviço por mais de um profissional, simultaneamente. A maioria (61\%) dos salões possuía um único banheiro, $35 \%$ deles possuíam dois ou mais e, em $2 \%$, não havia banheiro.

Em estudo com cabeleireiros, identificou-se um padrão de estabelecimentos menores na Europa, sendo que a maioria $(45,7 \%)$ deles apresentava um ou dois profissionais trabalhando $(24,8 \%)^{(11)}$. Há de se considerar que, em lugares com dimensões pequenas, com muitos móveis, há uma maior probabilidade da ocorrência de acidentes com material perfurocortante. Não há uma norma nacional que determine a estrutura física de estabelecimento do segmento da beleza e estética. Em Goiás (1995), a Portaria n. ${ }^{\circ} 456$ estabelece uma área mínima de $8 \mathrm{~m}^{2}$, com adição de $4 \mathrm{~m}^{2}$ por cada cadeira instalada ${ }^{(12)}$. Algumas legislações, em outros estados e municípios, determinam a existência de pelo menos um gabinete sanitário, exclusivo, podendo ser utilizado os coletivos quando os salões estiverem instalados em shopping centers ${ }^{(4,10,12-14)}$. Em outra pesquisa, identificou-se adequação sanitária para apenas $31 \%$ dos salões visitados, atentando-se para a possibilidade de contaminações por microrganismos, inclusive da microbiota intestinal $^{(15)}$.

No que diz respeito ao tipo de acabamento das paredes, em todo salão, inclusive dos banheiros e dos mobiliários, $92 \%$ deles eram de materiais que permitiam a limpeza e $91 \%$ possuíam um local exclusivo para armazenar materiais e produtos de limpeza para pisos/paredes. De acordo com o Decreto n. ${ }^{\circ}$ 23.915 , de 13 de janeiro de 2004, os salões de cabeleireiros, institutos de beleza, estética e podologia deverão possuir, em suas dependências, pisos e paredes de superfícies lisas, compostos de material compacto, resistente à lavagem e ao uso de desinfetantes e de fácil limpeza e higienização, mantendo suas instalações físicas devidamente conservadas e asseadas $^{(13)}$

Em 43\% dos estabelecimentos, foi identificado um local próprio destinado à limpeza de artigos (instrumentais de manicures, escovas, vasilhames), enquanto os demais realizavam a limpeza em pias dispostas em sala externa à área de atendimento do salão (39\%) e no banheiro $(29,4 \%)$. Demais dados encontram-se na Figura 1. Para $30 \%$ dos salões de beleza, havia uma única pia e essa era destinada a todo o tipo de lavagem (tecidos, artigos, lavagem das mãos) e ao descarte de produtos químicos, que escoavam diretamente na rede de esgoto. Baixa disponibilidade de local próprio para limpeza de artigos foi identificada no estado de São Paulo, com pia exclusiva para lavagem de artigos em apenas $2,5 \%$ e $7 \%$ dos salões e área para preparar os artigos para processamento em $4 \%$ e $10 \%{ }^{(7,16)}$.

Em 45\% dos salões, foi observada uma sala exclusiva e separada das demais para abrigar o equipamento de esterilização. Os demais encontravam-se na recepção, próximo ao local de atendimento, debaixo de escadas, vãos e áreas externas abertas. Diretrizes legais recomendam que os equipamentos para este fim estejam em locais exclusivos para o processamento e que haja, preferencialmente, armário fechado para acondicionamento dos artigos processados protegidos da umidade, poeira e manipulação contínua de pessoas ${ }^{(4,13,17)}$. Contudo, em salões de beleza, nem sempre é possível atender às especificações supracitadas, por estarem, normalmente, localizados em pequenos espaços, diferente do âmbito hospitalar.

A maioria utilizava o calor seco - estufa $(37 \%)$ e o "forninho" (24,7\%), equipamento que submete artigos ao calor seco e não possui termômetro externo para o registro da temperatura ou o controle do tempo da exposição, como método de esterilização, sendo 
observado o calor úmido, por meio da autoclave,

em 35,3\% dos estabelecimentos (Figura 2).

Figura 2: Características relativas à limpeza e esterilização dos artigos utilizados nos salões de beleza. Belo Horizonte - MG, 2013. Total $=235$.

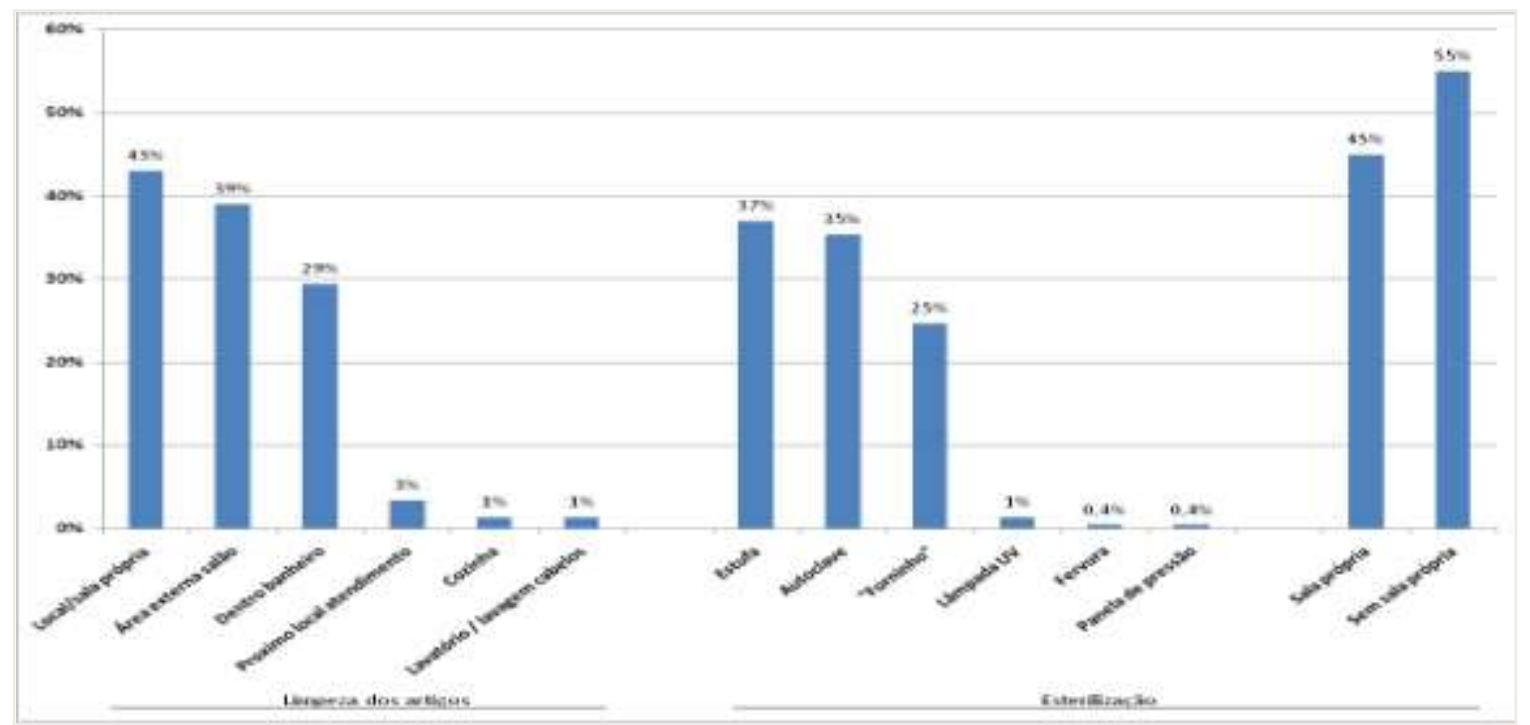

Fonte: Dados da pesquisa.

O calor seco foi o método mais identificado nos salões $(61,7 \%$ - Forno de Pasteur/estufa, "forninho") que, apesar de ainda não ser proibido em salões de beleza, não deve ser indicado como primeira escolha, entretanto, é o equipamento de maior adesão dos profissionais devido ao baixo custo $^{(17)}$. Existem outros métodos de processamento como a radiação gama, o gás óxido de etileno e o plasma peróxido de hidrogênio; contudo, são métodos complexos e de alto custo ${ }^{(17)}$. Um processo seguro, eficiente, rápido e uma técnica acessível aos profissionais da beleza e estética é o calor úmido, representado pela autoclave ou vapor saturado sob pressão ${ }^{(17,18)}$.

O processamento por autoclave (calor úmido) foi observado em apenas 35,3\% dos estabelecimentos. Em outros estudos, a utilização referida deste equipamento variou entre $1 \%$ e $79 \%$, entretanto, para alguns, os dados foram provenientes de afirmações e não da identificação direta do processo e do equipamento pelos pesquisadores ${ }^{(5,16,19)}$. Possivelmente, o reduzido uso se deve ao maior custo (cerca de $\mathrm{R} \$ \mathbf{1 . 7 0 0 , 0 / 4}$ litros a $\mathrm{R} \$$ $4.500,0 / 42$ litros) em comparação ao das estufas $(R \$ 150,0$ a $R \$ 900,0)$ ou, até mesmo, pelo pouco conhecimento e segurança do processo da autoclave $^{(5,7,19-21)}$.

Outros métodos de processamento (ultravioleta, fervura, panela de pressão doméstica) foram identificados e também são citados por outras pesquisas, mas eles são considerados ineficazes para a esterilização, além de serem proibidos para tal finalidade, por colocarem em risco a saúde da população ${ }^{(4-7,17}$, 22,23).

Quanto à garantia de qualidade do processamento de artigos, o uso de indicadores biológicos nas autoclaves é recomendado por agências de saúde nacionais e internacionais ${ }^{(17,24)}$. Nos salões analisados neste estudo, apenas 35,3\% possuíam autoclave e $33,2 \%$ permitiram a realização do teste, não havendo positividade determinada pelo crescimento bacteriano constituinte do indicador biológico. Num único salão foi referido, pelo entrevistado, a realização do controle do funcionamento do equipamento pelo indicador biológico, mas sem qualquer registro. A Resolução da Diretoria Colegiada (RDC), número 15, da Anvisa de 2012, determina que os monitoramentos do processamento de artigos devam ser registrados e guardados para consulta e avaliação de autoridades sanitárias ${ }^{(17)}$.

Em relação ao controle biológico, a maioria das publicações a este respeito refere-se a consultórios odontológicos ou ao ambiente hospitalar. Não há nenhuma publicação, até o momento, em que os pesquisadores tenham realizado o controle do funcionamento dos equipamentos de esterilização em salões. Entre as poucas publicações no segmento da beleza e estética, três revelaram, por meio de relato, a ausência ou baixa prática ( $2 \%$ a $5 \%$ ) para este 
controle, sem o cuidado de realizar e manter o registro com data, tipo de indicador utilizado e o resultado ${ }^{(5,7,16)}$.

Os indicadores biológicos são reconhecidos por retratarem o processo de esterilização, pois consideram todos os parâmetros (tempo, temperatura, penetração do vapor), garantindo, portanto, a segurança. Eles estão disponíveis, na forma de esporos do Bacillus stearothermophilus, para avaliar equipamentos que utilizam calor úmido (autoclave) e não mais para o calor seco (estufas), pois este método de processamento vem sendo desaconselhado. Esse controle biológico é relativamente simples, com verificação rápida do resultado em três horas ${ }^{(17)}$.

A característica e a frequência da limpeza/desinfecção das superfícies, mobiliários e piso nos salões de beleza foram também avaliadas neste estudo, conquanto que partindo das respostas ao questionário e não por observação direta. Para as superfícies e mobiliário, $46 \%$ das manicures/pedicures relataram que a limpeza/desinfecção é realizada utilizando-se água, sabão e desinfetante; $20,4 \%$ das manicures/pedicures relataram a utilização de água e sabão; $16,7 \%$, de produtos domésticos e $8,9 \%$ não conseguiram definir um método, por não haver qualquer rotina de limpeza ou pelo uso de produtos variados. A frequência da limpeza foi referida como diária por $74,5 \%$ das entrevistadas e, a cada cliente, por apenas 2,6\% (Figura 3).

No segmento da beleza e estética, parece não haver muita preocupação pelos profissionais no sentido de limpar e desinfetar as superfícies, nos salões de beleza, como mobiliários, cadeiras e pisos. Todas as entrevistadas relataram a realização da limpeza e desinfecção de superfícies, contudo, com frequência e produtos inadequados. Houve a referência para o uso de técnicas domésticas com produtos inespecíficos ou inefetivos, como o álcool com graduações variadas (exemplo: $54^{\circ} \mathrm{GL}$ ) e, ainda, o uso de tecidos ou espanadores, o que favorece a dispersão de poeira, podendo carrear microrganismos $^{(12,18)}$. Sabe-se que o uso de artigos sem a devida limpeza/desinfecção ou descarte propicia a contaminação e a possível transmissão de patógenos, como as hepatites virais, que constituem um grande problema de saúde pública mundial. $O$ vírus da hepatite $B$ pode resistir em superfícies e objetos por um período de até sete dias em temperatura ambiente, portanto, a limpeza e desinfecção do ambiente são importantes na prevenção de contágios ${ }^{(25,26)}$.

Pesquisas no Brasil e no Marrocos, com profissionais do segmento da beleza, mostraram a mesma realidade, com pouca adesão à limpeza ou desinfecção dos mobiliários e outras superfícies nos salões ${ }^{(7,20,27)}$. Essas medidas não são consideradas necessárias pelos profissionais e, portanto, não são realizadas rotineiramente entre $o$ atendimento de um cliente e outro e, nem mesmo, ao fim do expediente $e^{(18,20,27)}$.

Em relação à limpeza e desinfeç̧ão do piso, todas as entrevistadas revelaram a execução de varredura do chão fazendo o uso de vassouras (varredura seca). Subsequente à varredura, a maioria citou a aplicação de água, sabão e desinfetante $(83,4 \%)$ (Figura 3). A maioria das entrevistadas alegou que a frequência da limpeza ocorre diariamente $(89,3 \%)$ e $0,9 \%$ afirmou que ela ocorre sem critério e de acordo com a necessidade.

No ambiente de trabalho, nos salões de beleza, deve-se considerar a limpeza ou desinfecção de piso, paredes, teto, portas, janelas e o mobiliário, compreendendo cadeiras, mesas, balcões, bancadas e pias, além dos equipamentos eletroeletrônicos. Tais superfícies devem ser limpas ou desinfetadas a cada cliente, utilizandose água e sabão e/ou friç̧ão com álcool a $70 \%$. Piso e paredes devem ser de fácil limpeza, não sendo indicada a varredura seca, mas, sim, a úmida, diariamente, e ao final do dia, uma limpeza mais rigorosa do piso com o hipoclorito de sódio ou quaternário de amônio ${ }^{(13,24,28)}$. 
Figura 3: Método e frequência da limpeza de superfícies, mobiliário e pisos citados pelas manicures/pedicures participantes do estudo. Belo Horizonte, 2013. Total= 235.

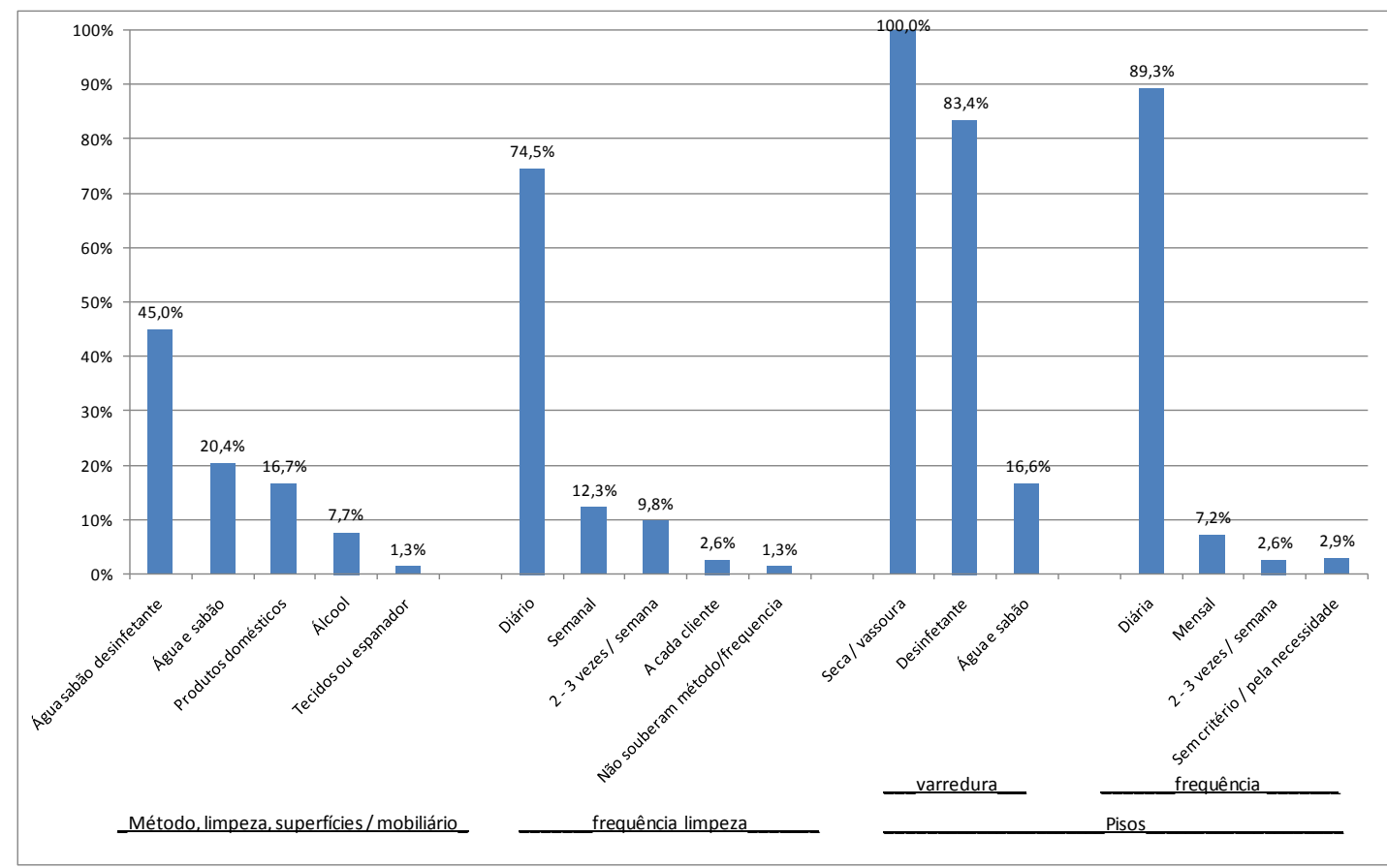

Fonte: Dados da pesquisa.

A presença do recipiente de parede rígida para o descarte de material perfurocortante foi identificada em apenas $23 \%$ dos estabelecimentos e $70 \%$ deles possuíam todas as lixeiras com tampa, localizadas em áreas de fácil acesso. Nas duas legislações sanitárias para salões de beleza do estado de Minas Gerais, não há menção detalhada quanto à estrutura de um salão no que diz respeito ao tamanho mínimo ou proporção entre tamanho e número de funcionários, quantidade e condições de sanitários, locais e dispositivos adequados para permitir a higienização de mãos, descarte de artigos de uso único e perfurocortantes. Contudo, sabe-se que a VISA tem realizado inspeções sanitárias com roteiros de inspeção que identificam e recomendam infraestrutura, equipamentos e artigos mínimos para salões de beleza, além da formulação de cartilhas de orientações $^{(18)}$. Em outros estados e municípios, há legislações mais atuais que detalham as recomendações referentes ao espaço físico, ao descarte de materiais de uso único, atualização vacinal dos profissionais, o uso de equipamento de proteção individual, higienização de mãos e processamento dos $\operatorname{artigos}^{(10,13,14,28)}$.

\section{CONCLUSÃO}

Os resultados gerais da pesquisa são preocupantes na medida em que refletem um risco presumido da transmissão de agentes microbianos causadores de doenças com relevantes impactos socioeconômicos, uma vez que os salões de beleza, no geral, não atendem às exigências mínimas relativas às medidas de biossegurança, as quais minimizariam os riscos biológicos ocupacionais e aos clientes.

Algumas inadequações foram percebidas e aumentam o risco biológico: a oferta de mais de um tipo de serviço com maior demanda de clientes, a informalidade dos profissionais, problemas na estrutura física dos estabelecimentos (ausência de banheiros, pias em quantidade insuficiente) e baixa adesão a métodos de processamento adequados de material que são recomendados pelos órgãos de saúde.

As limitações da pesquisa envolvem a impossibilidade da observação de todos os processos, já que alguns foram referidos sem a comprovação de suas afirmações, como por exemplo, os métodos e a frequência de limpeza e desinfecção de superfícies. 
Diante da situação apresentada, destaca-se a necessidade de atenção à atuação dos profissionais em salões de beleza pelas vigilâncias sanitárias, promovendo ações educativas, capacitações aos profissionais a fim de reduzir os riscos biológicos individuais e coletivos, por meio de uma prática profissional segura e eficiente. A exigência de formação técnica dos profissionais e proprietários de salões seria de especial valia na perspectiva de redução das inadequações encontradas no segmento da beleza e estética.

\section{REFERÊNCIAS}

1. Dweck RH, Di Sabbato A. A beleza e o mercado de trabalho: uma perspectiva de gênero. Gênero. 2006 [citado em 5 jan 2017];6-7(1):95-128. Disponível em: http://www.revistagenero.uff.br/index.php/r evistagenero/article/viewFile/348/260

2. Brasil. Lei № 12.592 , de 18 de janeiro de 2012. Dispõe sobre o exercício das atividades profissionais de cabeleireiro, barbeiro, esteticista, manicure, pedicure, depilador e maquiador. Brasília, DF: Diário Oficial da União; 2012 [citado em 5 jan 2017]. Disponível em: http://www.planalto.gov.br/ccivil 03/ ato20 11-2014/2012/lei/l12592.htm

3. Moore JE, Miller BC. Skin, hair, and other infections associated with visits to barber's shops and hairdressing salons. Am J Infect Control. $2007 \quad$ Apr;35(3):203-4. https://doi.org/10.1016/i.ajic.2006.10.010

4. Campo Grande (MS). Lei № 3.632, de 30 de junho de 1999. Disciplina os serviços de cabeleireiros, barbeiros, manicuras, pedicures, limpeza de pele e serviço afins e dá outras providências. Campo Grande: Diário Oficial do Município de Campo Grande; 1999 [citado em 5 jan 2017]. Disponível em: https://cm-campo-

grande.jusbrasil.com.br/legislacao/247932/lei -3632-99

5. Moraes JT, Barbosa FI, Costa TRS, Ferreira AF. Hepatite B: conhecimentos dos riscos e adoção de medidas de biossegurança por manicures e pedicures de Itaúna/ MG. Rev Enferm Cent Oeste Mineiro. 2012;2(3):34757.

\section{https://dx.doi.org/10.19175/recom.v0i0.225}

6. Wazir MS, Mehmood S, Ahmed A, Jaddon HR. Awareness among barbers about health hazards associated with their profession. J Ayub Med Coll Abbottabad. 2008 AprJun;20(2):35-8.
7. Oliveira ACDS. Estudo da estimativa de prevalência das hepatites B e C e da adesão às normas de biossegurança em manicures e/ou pedicures do município de São Paulo [tese]. São Paulo: Programa de Pós-graduação em Ciências, Coordenadoria de Controle de Doenças da Secretaria de Estado da Saúde de São Paulo; 2009.

8. Instituto Brasileiro de Geografia Estatística (IBGE). Censo Demográfico. 2010 [citado em 5 jan 2017]. Disponível em: http://www.ibge.gov.br/home/estatistica/po pulacao/censo2010

9. Paraná (Estado). Resolução № 204, de 17 de março de 2009. Dispõe sobre as condições para instalação e funcionamento dos Estabelecimentos de Podologia. Paraná: Secretaria de Estado da Saúde; 2009 [citado em 5 jan 2017]. Disponível em: http://www.saude.pr.gov.br/arquivos/File/Le gislacao/estudual resolucao/RES SESA204 0 9Podologia.pdf

10. Amodio E, Di Benedetto MA, Gennaro L, Maida $\mathrm{CM}$, Romano N. Knowledge, attitudes and risk of HIV, HBV and HCV infections in hairdressers of Palermo city (South Italy). Eur J Public Health. $2010 \quad$ Aug;20(4):433-7. https://doi.org/10.1093/eurpub/ckp178

11. Goiás (Estado). Portaria № 456, de 10 de junho de 1995. Estabelece Normas Técnicas Relativa ao Saneamento e ao Meio Ambiente. [Goiânia]: Secretaria Estadual de Saúde;10 jun 1995 [citado em 5 jan 2017]. Disponível em: $\quad$ http://docplayer.com.br/1962080Portaria-n-456-95-ses-go-de-10-de-junho-de1995-norma-tecnica-relativa-ao-saneamentoe-ao-meio-ambiente-introducao.html

12. Rio de Janeiro (RJ). Decreto № 23.915 , de 13 de janeiro de 2004. Dispõe sobre o licenciamento sanitário a que estão sujeitos os salões de cabeleireiros, institutos de beleza, estética, podologia e congêneres. Rio de Janeiro, RJ: Diário Oficial do Município, 14 jan 2004 [citado em 5 jan 2017]. Disponível em:

http://www.rio.ri.gov.br/dlstatic/10112/5125 745/4132393/DecretoMunicipaln23915.pdf

13. Jaraguá do Sul (SC). Lei № 3.865, de 29 de junho de 2005. Autoriza o município de Jaraguá do Sul a estabelecer normas para quem explora as atividades de cabeleireiro, barbeiro, manicure, pedicure e estética. [Florianópolis]: Diário Oficial dos Municípios de Santa Catarina: jun 2005. [citado em 5 jan 
2017]. Disponível em: https://camaramunicipal-de-jaragua-do-

sul.jusbrasil.com.br/legislacao/758244/lei3865-05

14. Corrales Ramírez CL, Sánchez LC, Olaya Tunjano JC, López Gómez CP. Evaluación de la efectividad de los procesos de desinfección de los utensilios em salones de belleza en un municipio de Cundinamarca. NOVA. 2007[citado em 5 jan 2017];5(7):65-9. Disponível em: http://www.unicolmayor.edu.co/invest nova /NOVA/NOVA7 65 69.PDF

15. Diniz AF, Matté GR. Procedimentos de biossegurança adotados por profissionais de serviços de embelezamento. Saude Soc. 2013;22(3):751-9.

https://doi.org/10.1590/S0104-

$\underline{12902013000300009}$

16. Ministério da Saúde (BR). Agência Nacional de Vigilância Sanitária. Resolução - RDC № 15, de 15 de março de 2012. Dispõe sobre requisitos de boas práticas para o processamento de produtos para saúde e dá outras providências. Brasília, DF: Diário Oficial da União, 2012 [citado em 5 jan 2017]. Disponível em: http://bvsms.saude.gov.br/bvs/saudelegis/an visa/2012/rdc0015 $15 \quad 03 \quad 2012 . h t m l$

17. Starling CCD, Pulier VL. Boas práticas de funcionamento para institutos e salões de beleza, estética, cabeleireiro e similares. Belo Horizonte: Secretaria Municipal de Saúde; 2015.

18. Araújo DCSA; Guerreiro JV. Conhecimentos e medidas de biossegurança adotadas por manicures autônomas do município de Mamanguape - PB. Vigil Sanit Debate. 2016;4(3):103-9.

https://doi.org/10.22239/2317-269x.00751

19. Oliveira ACDS, Focaccia R. Survey of hepatitis $B$ and $C$ infection control: procedures at manicure and pedicure facilities in São Paulo, Brazil. Braz J Infect Dis. 2010 SepOct;14(5):502-7.

https://doi.org/10.1016/S1413-

8670(10)70100-8

20. Johnson IL, Dwyer JJM, Rusen ID, Shahin R, Yaffe B. Survey of Infection Control Procedures at manicure and Pedicure Establishments in North York. Can J Public Health. 2001 Mar-Apr [citado em 5 jan 2017];92(2):134-7. Disponível em: http://journal.cpha.ca/index.php/cjph/article $\angle$ view $/ 70 / 70$
21. Arulogun OS, Adesoro MO. Potential risk of HIV transmission in barbering practice among professional barbers in Ibadan, Nigeria. Afr Health Sci. 2009 Mar [citado em 5 jan 2017];9(1):19-25. Disponível em: https://www.ncbi.nlm.nih.gov/pmc/articles/P MC2932524

22. Belo Horizonte (MG). Secretaria Municipal de Saúde. Portaria № 11, de 02 de junho de 1997. Aprova Norma Técnica referente às exigências sanitárias para salões de beleza, barbearias, manicures, pedicures e similares, na forma do anexo à presente Portaria. Belo Horizonte: Diário Oficial do Município, ano 3 , № 421, 20 jun 1997 [citado em 5 jan 2017]. Disponível em: http://portal6.pbh.gov.br/dom/iniciaEdicao.d o?method=DetalheArtigo\&pk=1025641

23. Ministério da Saúde (BR). Portaria № 2.616, de 12 de maio de 1998. [D]ispõe sobre a obrigatoriedade da manutenção pelos hospitais do país, de Programa de Controle de Infecções Hospitalares. Brasília, DF: Diário Oficial da União; 1998 [citado em 5 jan 2017]. Disponível em: http://bvsms.saude.gov.br/bvs/saudelegis/g m/1998/prt2616 1205 1998.html

24. World Health Organization. Department of Communicable Diseases Surveillance and Response. Hepatitis B. Geneva: WHO; 2002 [citado em 5 jan 2017]. Disponível em: http://apps.who.int/iris/bitstream/10665/67 746/1/WHO CDS CSR LYO 2002.2 HEPATITI S B.pdf

25. Ministério da Saúde (BR). Manual de aconselhamento em hepatites virais. Brasília, DF: Ministério da Saúde; 2005.

26. Zahraoui-Mehadji M, Zahraoui Baakrim M, Laraqui S, Laraqui O, El Kabouss $Y$, Verger $C$, et al. Risque infectieux lié au sang chez les coiffeurs-barbiers traditionnels et leurs clients au Maroc. Sante. 2004 OctDec;14(4):211-6. 2004 Out-Dec[citado em 5 jan 2017]; 14(4): 211-6. Disponível em: http://www.jle.com/fr/revues/san/edocs/risque infectieux lie au sang chez les coiffeurs barbiers traditionnels et leurs $\mathrm{cl}$ ients au maroc 264851/article.phtml?tab=t exte

27. Paraná (Estado). Secretaria de Estado da Saúde. Código de Saúde do Paraná. Curitiba: SESA; 2002 [citado em 5 jan 2017]. Disponível em:http://www.saude.pr.gov.br/arquivos/Fil e/Codigo Saude.pdf 
Nota: Pesquisa financiada pelo Programa Pesquisador Mineiro (PPM) - 2011 Processo: no 00340-11 e pelo Fundo de Incentivo à Pesquisa da Puc Minas processo no 2010/5790-S2. Resultados oriundos de Tese-Doutorado pela UFMG.

Recebido em: 14/03/2017

Aprovado em: 08/03/2018

Endereço de correspondência:

Juliana Ladeira Garbaccio

Rua Maria Fortunata Rothéia, 432

CEP: 31330-642 - Belo Horizonte/MG - Brasil

E-mail: julianapuciec@gmail.com 